\title{
Derecho, marxismo y método ${ }^{1}$
}

\author{
Law, Marxism and Method
}

Direito, Marxismo e Método

Droit, marxisme et méthode

法律, 马克思主义与方法

\section{Paul O'Connell \\ Universidad de Londres - Inglaterra}

Revista Derechos en Acción ISSN 2525-1678/ e-ISSN 2525-1686

Año 5/No 14, Verano 2019-2020 (21 diciembre a 20 marzo), 254-273

DOI: https://doi.org/10.24215/25251678e359

ORCID: https://orcid.org/0000-0002-5674-0601

Recibido: $15 / 12 / 2019$

Aprobado: 10/02/2020

Resumen: El Derecho es crucial para el mantenimiento y la reproducción del capitalismo. A pesar de que Marx nunca produjo una teoría integral del Derecho, el Estado y los derechos, hay mucho de ello en su trabajo y

1 Traducción, edición y corrección: María Gracia Villarreal Rodríguez (Estudiante de licenciatura en Ciencias Jurídicas, Escuela de Derecho, U. Católica del Norte, sede Coquimbo, Chile. Correo de contacto: gracia.vr02@gmail.com) y Pablo Gres Chávez (Abogado, Universidad de Chile. Candidato a Doctor en Derecho, Universidad de Buenos Aires. Profesor de Filosofía y Teoría del Derecho, Escuela de Derecho, U. Católica del Norte, sede Coquimbo, Chile. Correo de contacto: pablo.gres@ucn.cl).

2 Profesor de Derecho la Escuela de estudios orientales y africanos de la Universidad de Londres (SOAS University of London). Su investigación se centra en derechos humanos, teoría jurídica y enfoques marxistas del derecho. Ha publicado sobre derechos económicos y sociales, sobre la relación entre los derechos humanos y la globalización, y sobre marxismo, movimientos sociales y derechos humanos. Es autor de Masking Barbarism: Human Rights in the Contemporary Global Order (Hart 2018) y editor del Manual sobre derecho y marxismo (Edward Elgar, de próxima publicación). Correo de contacto: po5@soas.ac.uk. REDEA agradece especialmente al autor su autorización para traducir y publicar este trabajo y a los traductores y editores del presente texto. 
en la tradición marxista más amplia, que pueden ayudarnos a entender la naturaleza y el rol del Derecho en el capitalismo contemporáneo. Este artículo esboza algunos de los recursos claves desde el interior de la teoría marxista, que pueden ayudarnos a desarrollar una comprensión marxista del Derecho, el Estado y los derechos en la actualidad. Específicamente el foco se centra en la cuestión del método, extrayendo tres hilos claves del propio trabajo de Marx: (i) la importancia del análisis dialéctico materialista, (ii) la naturaleza históricamente específica y transitoria del capitalismo, y (iii) la centralidad del antagonismo de la lucha de clases. El argumento propuesto aquí, en suma, es que las explicaciones marxistas del Derecho, el Estado y los derechos deberían poner en primer plano de referencia estos puntos analíticos, para hacer inteligible el rol del Derecho, y comenzar a esbozar cómo los movimientos hacia el cambio social fundamental podrían entenderse y ligarse con el Derecho.

Palabras clave: Derecho, Estado, Derechos Humanos, Marxismo, Método, Materialismo Dialéctico, Lucha de Clases

Abstract: The law is crucial to the maintenance and reproduction of capitalism. Although Marx never produced a comprehensive theory of law, state and rights, there is much in his work about this and in the wider Marxist tradition that can help us understand the nature and role of law in contemporary capitalism. This article outlines some of the key resources from within Marxist theory that can help us develop a Marxist understanding of law, state and rights today. Specifically the focus is on the question of method, drawing out three key threads from Marx's own work: (i) the importance of dialectical materialist analysis, (ii) the historically specific and transitory nature of capitalism, and (iii) the centrality of the antagonism of class struggle. The argument put forward here is that Marxist explanations of law and the state should bring these analytical points to the fore, to make the role of law intelligible and to begin to outline how movements towards fundamental social change might be understood and linked to law.

Keywords: Law, State, Human Rights, Marxism, Method, Dialectical Materialism, Class Struggle

Resumo: 0 direito é crucial para a manutenção e a reprodução do capitalismo. Apesar de que Marx nunca produziu uma teoria integral do Direito, o estado e os direitos, há muito disso em seu trabalho e na tradição 
marxista mais ampla, que podem nos ajudar a entender a natureza e o papel do Direito no capitalismo contemporâneo. Este artigo descreve alguns dos principais recursos da teoria marxista que podem nos ajudar a desenvolver uma compreensão marxista do Direito, o Estado e os direitos na atualidade. Especificamente o foco está na questão do método, extraindo três linhas-chave do próprio trabalho de Marx: (i) a importância da análise materialista dialética, (ii) a natureza historicamente específica e transitória do capitalismo; e (iii) a centralidade do antagonismo da luta de classes. 0 argumento apresentado aqui, em resumo, é que as explicações marxistas do Direito, o Estado e os direitos deveriam colocar em primeiro plano esses pontos analíticos, para tornar inteligível o papel do Direito e começar a delinear como os movimentos em direção ao câmbio social fundamental poderia ser entendido e vinculado o Direito.

Palavras-chave: Direito, Estado, Direitos Humanos, Marxismo, Método, Materialismo Dialético, Luta de Classes

Résumé: Le droit est cruciale afin de maintenir et repruduire le capitalisme. Bien que Marx n'ait jamais produit une théorie complète du droit, l'état et les droits, il y en a beaucoup dans son travail et dans la tradition marxiste plus large. Cela peut nous aider à comprendre la nature et le rôle du droit dans le capitalisme contemporain. Cet article esquisse des certaines ressources clés dans la théorie marxiste, lesquels peuvent nous aider à développer une compréhension marxiste du droit, de l'État et des droits aujourd'hui. Spécifiquement, l'article se concentre sur la question de la méthode, en extrayant trois clés du travail de Marx: (i) l'importance de l'analyse dialectique matérialiste, (ii) la nature historiquement spécifique et transitoire du capitalisme, et (iii) la centralité de l'antagonisme de la lutte des clases. L' argument proposé, est que les explications marxistes de la loi, de l'État et des droits devraient mettre au premier plan ces points d'analyse afin de faire inteligible le rôle du droit et commencer à décrire comment les mouvements vers un changement social fondamental pourraient être compris et liés au droit.

Mots-clés: droit, État, droits de l'homme, marxisme, méthode, matérialisme dialectique, lutte de classe

摘要：法律对于维持和复制资本主义至关重要。尽管马克思从未提 出过全面的法律, 国家和权利理论, 但在他的著作和更广泛的马克 思主义传统中有很多理论, 这可以帮助我们理解法律在当代资本主 
义中的性质和作用 。本文概述了马克思主义理论中的一些关键资 源，这些资源可以帮助我们发展对当今法律，国家和权利的马克思 主义理解。具体来说, 重点放在方法问题上, 从马克思的著作中汲取 了三个关键线索：(i)辩证唯物主义分析的重要性，（ii）资本主义的 历史特定性和暂时性，以及(iii) 资本主义的中心性。阶级斗争的对 抗。简而言之, 这里提出的论点是, 马克思主义对法律, 家和权利的 解释应使这些分析要点脱颖而出, 以使法律的作用易于理解, 并开 始概述向变革的方向。基本的社会可以被理解并与法律联系起来。

关键词: 法律, 国家, 人权, 马克思主义, 方法, 辩证唯物主义, 阶级斗争

\section{Introducción}

El Derecho, en sus múltiples formas, juega un papel crucial en el mantenimiento y reproducción del modo de producción capitalista. Derechos, normas de propiedad, contratos, códigos penales, constituciones, tratados internacionales y las tradiciones jurisprudenciales que se desarrollan a su alrededor, todos sirven para estructurar y legitimar las relaciones sociales dentro de las sociedades capitalistas. A pesar de la importancia del Derecho, Marx nunca produjo una teoría integral del Derecho, el Estado y los derechos, a la par con su crítica a la economía política en el Capital (Cain 1974; Fine 1984). Como resultado de esto, la primera generación de marxistas nunca desarrolló realmente una teoría completa del Estado burgués (Lukács 1970, 61), y "toda la tradición Marxista clásica legó un silencio mortal" sobre cuestiones del Derecho, el Estado y los derechos (Hunt 1992, 110).

A lo largo del siglo XX, particularmente en momentos de pronunciadas crisis capitalistas, varios prominentes marxistas buscaron desarrollar explicaciones exhaustivas del papel del Derecho, el Estado y los derechos en la reproducción del capitalismo. Cada uno de estos teóricos desde Pashukanis (1978) y Renner (1949) a Althusser (1971), Poulantzas (1978) y Thompson (1975), realizaron importantes intervenciones y mejoraron, de una forma u otra, los análisis marxistas del Derecho, el 
Estado y los derechos. Al mismo tiempo, cada una de estas intervenciones ha sido diferente: desde la unilateral y no dialéctica presentación de la legalidad burguesa en Pashukanis, hasta el reformismo fuera de lugar de Renner, el quietismo político de Althusser, y la fe injustificada de Thompson en el imperio de la ley. Así las cosas, es muy útil revisar la obra Marxismo de Marx (Draper 1977, 18) para orientar los análisis marxistas del Derecho, el Estado y los derechos hoy en día ${ }^{3}$.

En esta breve intervención, el argumento principal presentado es que desde el método de Marx (ampliamente concebido) es el lugar desde el que más podemos ganar en el desarrollo del análisis del Derecho, el Estado y los derechos de hoy en día. En particular, se argumentará que hay tres temas claves en el trabajo de Marx que deben informar los enfoques marxistas para el estudio del Derecho, el Estado y los derechos, a saber: (i) la centralidad del materialismo dialectico; (ii) reconocer la naturaleza del capitalismo como la históricamente contingente y transitoria; y (iii) poner en primer plano el antagonismo de clases como central para entender la dinámica de las relaciones sociales capitalistas.

\section{La centralidad del método}

Las obras recopiladas de Marx y Engels contienen numerosas referencias discretas al Derecho, el Estado y los derechos (Cain y Hunt 1979). Sin embargo, en estas diversas referencias no hay una teoría o perspectiva coherente y consistente. Por ejemplo, en La Ideología Alemana, Marx y Engel declaran su oposición inequívoca al Derecho (Marx y Engels 1845/46, 209), mientras que más tarde en el volumen I de El Capital (Marx 1867, Capítulo 10) y en su discurso inaugural de la Asociación Internacional de Trabajadores (Marx 1864), Marx elogia la exitosa lucha para

\footnotetext{
3 Por su puesto, hay muchos estudios interesantes sobre la relación entre el Derecho y el Marxismo, más allá del trabajo de estos pensadores canónicos en la tradición marxista. Para una descripción general y útil del campo, consulte el repositorio mantenido en: https:// legalform.blog.
} 
tener una jornada laboral de diez horas consagrada legalmente, como triunfo para la clase obrera. En El Manifiesto Comunista, el Estado se interpreta de manera puramente instrumental como un comité para gestionar los asuntos de la clase dominante (Marx y Engel 1848 y 1890) mientras que en otras ocasiones se aprecia y enfatiza la autonomía relativa (Engels 1886 y 1890). Y finalmente, a través de las voluminosas obras seleccionadas de Marx y Engels, los derechos, a la vez, ridiculizados y defendidos en diferentes momentos ( $\mathrm{O}^{\prime}$ Connell 2018).

Como tal, hay poco que ganar con lo que Hal Draper llama "repetición de citas sin sentido" (Draper 1977, 17), o intentado sostener una teoría marxista completa del Derecho, el Estado y los derechos, en esta o aquella declaración o argumento aislado. No hay una sola o definitiva teoría marxista del Derecho, el Estado y los derechos presentada en la obra de Marx. Esto es porque Marx, a pesar de su ambición, "no produjo, como a veces se supone, una teoría de todo" (Harvey 2012, 5). En lugar de respuestas integrales sobre cómo abordar y pensar acerca del papel del Derecho, el Estado y los derechos bajo el capitalismo, lo que obtenemos de Marx son "sugerencias metodológicas sobre las preguntas que deben formularse y por dónde empezar respondiéndolas" (Hunt 2004, 602). Este punto sobre la centralidad del método se releva aún más por Lukács, quién incluso sostuvo que:

"el marxismo ortodoxo, por tanto, no implica la aceptación acrítica de los resultados de investigaciones de Marx. No es la "creencia" en esta o aquella tesis, ni la exégesis de un libro "sagrado". Por el contrario, la ortodoxia se refiere exclusivamente al método. Es la convicción científica de que el materialismo dialéctico es el camino hacia verdad y que sus métodos sólo pueden desarrollarse, expandirse y profundizarse a lo largo de las líneas establecidas por sus fundadores. Es la convicción, además, de que todos los intentos de superarlo o "mejorarlo" lo han llevado y deben conducir a una simplificación excesiva, a la trivialidad y al eclecticismo" (Lukács 1971, 1)”. 
Podemos preferir evitar el lenguaje de la ortodoxia por anticuado o inútil, pero incluso teniendo en cuenta eso, el punto que Lukács hace aquí es de importancia central.

Es decir, si bien podemos aprender de lo que Marx (y Engels) dijeron específicamente sobre el Derecho, el Estado y los derechos, no hay necesidad o valor en simplemente tratar de encontrar la "correcta" postura marxista sobre el Derecho, el Estado y los derechos. Más bien, podemos y debemos centrar nuestra atención sobre el marco metodológico que nos proporciona el trabajo de Marx y usarlo como punto de partida para desarrollar el análisis marxista del Derecho, el Estado y los derechos acorde a los desafíos del capitalismo de hoy en día.

\section{Materialismo dialectico}

C.L.R. James sostiene que es "imposible lidiar con el marxismo" a menos que sea sobre las bases del materialismo dialectico (James 1999, 44). Similarmente, Bertell Ollman argumenta que todas "las teorías de Marx han sido moldeadas por su perspectiva dialéctica [...] y es solo al entender la dialéctica que estas teorías pueden entenderse, evaluarse y ponerse en práctica adecuadamente" (Ollman 2003, 4). Es importante reconocer ambos elementos del fundamento metodológico de Marx - la dialéctica y el materialismo. Estos dos elementos están relacionados de manera crucial e integral entre sí- como dice Chase, dentro de este esquema, el materialismo proporciona la hoja de ruta, pero sería inútil sin la brújula suministrada por dialéctica (Chase 1997, 33 Como el propio Marx señaló, tomó el método dialéctico desarrollado por Hegel y lo revolucionó, al cambiar el enfoque de las contradicciones abstractas entre ideas, por identificar las contradicciones materiales en la vida social (Marx 1867, 102-103).

La apropiación de Marx de los aspectos del método dialéctico de Hegel (abstracción, contradicción, negación, etc.) se ve aumentada por su énfasis en el materialismo. En su bien conocido Prefacio a la Contribución a la Crítica de la Economía Política, que Marx elaboró sobre su filosofía materialista, señaló 
que con el tiempo sus estudios lo llevaron a la conclusión de que "ni las relaciones jurídicas, ni las formas políticas podrían ser comprendidas ya sea por ellas mismos o sobre la base de un llamado desarrollo general de la mente humana, sino que, por el contrario, se originan en las condiciones materiales de la vida" (Marx 1859, 262).

Marx desarrolla aún más este punto, cuando argumenta que "en la producción social de su existencia, los hombres inevitablemente entran en relaciones, las cuales son independientes de su voluntad, es decir, relaciones de producción propias de una determinada etapa en el desarrollo de sus fuerzas materiales de producción. La totalidad de esas relaciones de producción constituye la estructura económica de la sociedad, el fundamento real, sobre el cual surge una superestructura jurídica y política y a la cual corresponden formas definidas de conciencia social. El modo de producción de la vida material condiciona el proceso general de la vida social, política e intelectual. No es la conciencia de los hombres la que determina su existencia, sino que su existencia social determina su conciencia" (Ibíd., 263).

De esto se desprende que, al abordar cuestiones sobre el Derecho, el Estado y los derechos, los análisis marxistas deben comenzar subrayando las condiciones históricas y materiales específicas que hacen surgir formas jurídicas particulares. Al mismo tiempo, esto tiene que ser complementado con una comprensión dialéctica de las formas jurídicas específicas, no como cosas, sino como procesos y relaciones complejas y contradictorias. No estática y unilateral, sino que dinámica, contradictoria, y cambiante. Como señala Chase, la estasis "representa solo la apariencia, la contradicción en la verdad. Todo, de una extraña pero importante manera, está constantemente en el proceso de llegar a ser su opuesto" (Chase 1997, 39).

Adoptar este enfoque significa impugnar y rechazar interpretaciones del Derecho formalistas legalistas y liberales como la encarnación natural de la "razón humana" (Montesquieu 
1949/1748, 6). En cambio, los análisis marxistas deberían enfatizar las específicas y complejas vías mediante las cuales particulares formas legales o estatales se corresponden con y refuerzan el modo de producción prevaleciente. Esto no implica un despliegue simplista o mecánico de la metáfora base-superestructura. En lugar de aquello, los análisis marxistas pueden y deben reconocer la relativa autonomía que los regímenes jurídicos adquieren con el tiempo, además de siempre enfatizar el papel determinante en el modo de producción (Engels 1890). Debería subrayarse aquí, que es la producción de la plusvalía (en forma de ganancias, intereses y rentas) la que predomina dentro del modo de producción capitalista, y que esto es una relación social (dinámica, cambiante y contradictoria), más que una cosa material (Harvey, 2012, 15). En este contexto, el Derecho, el Estado y los derechos son elementos del complejo conjunto de relaciones sociales que contribuyen a la reproducción del capitalismo, y no solo reflejos epifenoménicos de la base material (Steinberg 2016).

De ello se deduce que los análisis marxistas deben tratar de evitar los relatos ahistórico, metafísicos y unidimensionales del Derecho, el Estado y los derechos realizados por críticos liberales y de izquierda liberal por igual. En lugar de valorar ciegamente las formas existentes o descartarlas sin más, los análisis marxistas deberían focalizarse en rastrear las relaciones materiales y concretas que producen o sostienen a las formas legales o estatales dadas. Junto con esto, los análisis marxistas deben estar atentos al carácter contradictorio, complejo y dinámico de las relaciones legales dadas. De lo contrario corren el riesgo de retroceder en relatos idealistas o metafísicos o críticos del Derecho, el Estado y los derechos que no tocan la realidad de las relaciones sociales y las posibilidades de un cambio fundamental.

\section{La especificidad del capitalismo}

El materialismo dialéctico debería ser un punto de partida para los análisis marxistas del Derecho, el Estado y los 
derechos. Sin embargo, este aspecto del método de Marx, en sentido estricto, necesita ser complementado con otros dos elementos cruciales. El primero de ellos, fluye casi directamente de la aplicación de Marx del materialismo dialéctico al estudio de la transformación social a través del tiempo. Es la contingencia histórica y la transitoriedad del modo de producción capitalista. Al respecto, Marx sostuvo que el aspecto racional y revolucionario de la dialéctica "incluye en su comprensión positiva de lo que existe un reconocimiento de su negación, simultáneamente" (Marx 1867, 103). De esto se deduce que la "sociedad actual no es un cristal sólido, sino un organismo capaz de cambiar y que está constantemente involucrado en un proceso de cambio" (Marx 1867, 93).

El segundo punto es tan importante como el primero. El modo de producción capitalista, con sus formas sociales concomitantes, emerge como una etapa histórica específica, que a su debido tiempo será reemplazado. Esto es lo que Paul Sweezy denomina una "importante premisa" para los marxistas: el carácter transitorio del capitalismo (Sweezy 1946, 22). Esto no implica certeza teológica, ni leyes férreas de desarrollo histórico, sino que el adoptar una comprensión del modo de producción capitalista y de sus formas sociales como contingente y transitorio, es crucial para la orientación de los análisis marxistas de cuestiones concretas en su amplio contexto histórico.

En el amplio esquema teórico de Marx, el capitalismo como una sociedad históricamente contingente no es estático, sino que está dividido por contradicciones fundamentales que presagian su transformación. Las contradicciones de clase (a las que volveremos más abajo) son centrales aquí. Como Rühle argumenta, para Marx, la lucha de clases se convierte en una "ley de evolución histórica" con "el socialismo como el resultado necesario y lógico de esa lucha" (Rühle 1929, 392). Este último punto proporciona una premisa política y teórica crucialmente importante para el análisis marxista, a saber, la inevitabilidad del socialismo. Esto ha sido bien dicho por James, quien argumenta que 
"[...] la inevitabilidad del socialismo permanece como una imperiosa necesidad para los marxistas en tanto concepción. La razón es esta: tenemos muchos hechos objetivos antes de nosotros, eventos históricos, una inmensa variedad de acontecimientos. Cuando los observas tienes que decidir cuál apoyas, cuál hará avanzar las perspectivas que tienes, y qué está actuando en contra de estas perspectivas. En otras palabras [...] cuáles lideran el avance a una sociedad socialista, y cuáles colaboran al avance de, lo que la concepción marxista ha denominado, la barbarie" (James 1999, 44).

La inevitabilidad del socialismo, en este entendido, proporciona un crucial "criterio de juicio" para desarrollar y orientar el análisis marxista (Ibid.).

Cuando se trata de los análisis marxistas sobre el Derecho, el Estados y los derechos, dos implicaciones claves dos implicaciones clave surgen de este aspecto del marco metodológico de Marx. El primero es que los análisis marxistas tienen que disputar y cuestionar la naturalidad de las formas legales y estatales existentes. El teórico burgués ${ }^{4}$ trata el capitalismo como algo natural, inevitable y evidente, y como tal considera las formas y relaciones legales existentes como "las relaciones necesarias que surgen de la naturaleza de las cosas" (Montesquieu 1748/1949, 1), o como los "componentes necesarios de una sociedad justa" (Harel 2014, 3). En contraste, una tarea central para los análisis marxistas es mostrar cómo surgen formas jurídicas particulares, no como el producto inevitable de la razón, sino de manera contingente, en contextos históricos específicos coloreados por el modo de producción prevaleciente.

El segundo punto crucial que sigue, es que no solo se dan formas legales y estatales históricamente contingentes, sino que también transitorias. Este último punto es particularmente

4 El término burgués se usa aquí para referirse a la amplia gama de pensadores que ven el orden capitalista "como la forma absoluta y última de producción social" en lugar de una histórica etapa transitoria del desarrollo" (Marx 1867, 96). 
importante hoy. Para Marx y Engels, la totalidad de su trabajo político y teórico se dedicó a construir y apoyar un movimiento que aboliría "el estado actual de las cosas" (Marx y Engels $1845 / 46,49)$. Por el contrario, gran parte del marxismo contemporáneo está marcado por un quietismo (Anderson, 1979) que, si bien se aferra a las formas de análisis marxista, ha roto con la idea fundamental del marxismo como teoría y práctica de la liberación humana. En cambio, el marxismo en esta línea "se convierte en una teoría de la dominación capitalista” (Holloway 2012, 516).

Curiosamente, llegamos a una posición en la que tanto la corriente principal (positivista, formalista, iusnaturalista) como las teorías críticas del Derecho terminan como dos caras de la misma moneda. La primera busca racionalizar o perfeccionar las formas jurídicas existentes, mientras que la segunda se involucra en una "sacudida" unilateral de las normas legales vigentes, pero ambas en última instancia conservan el modo de producción capitalista como premisa inalterable. En contraste con cualquiera de estas perspectivas, los análisis marxistas no deberían valorar el orden existente, ni sucumbir al fatalismo resignado. Apreciar la contingencia histórica y la fugacidad del capitalismo y sus formas legales y estatales concomitantes, permite el desarrollo de análisis que rechazan la falsa necesidad de las relaciones existentes (Sweezy 1946, 22), pero también proporciona un criterio para identificar, desarrollar y apoyar cambios que promuevan la causa más amplia de la transformación social fundamental.

\section{Lucha de clases}

El elemento final del marco metodológico de Marx es la centralidad de la lucha de clases. Sin tener el espacio para entrar en los debates sobre clase y análisis de clase con gran profundidad aquí, es importante hacer algunos breves puntos. La clase, para Marx, es la contradicción fundamental en el corazón del modo de producción capitalista (Wood 1988, Mészáros 1995). 
La explotación de clase es el factor definitorio dentro del análisis marxista, pero entendido adecuadamente, no desconoce, ni descarta las otras valencias de opresión, de importancia crucial, ya sea género, raza, casta o sexualidad. Finalmente, la clase en la tradición marxista se entiende mejor como la relación estructural de grupos específicos de personas para controlar la apropiación de la plusvalía (Draper 1977, 14). Crucialmente, lo que esto significa es que, independientemente de cómo las personas se definan subjetivamente y se comprendan a sí mismas, como millonarios temporalmente frustrados o lo que sea, la gran mayoría de las personas permanecen, bajo el capitalismo contemporáneo, dentro de la clase trabajadora (Mohun 2016).

Desde sus primeros trabajos filosóficos, hasta su economía política madura y todo lo demás, Marx enfatizó la centralidad del antagonismo de clase y la lucha de clases para su comprensión de cómo surgió, funciona y se desarrolla el capitalismo en el tiempo. En su Contribución a la crítica de la Filosofía del Derecho de Hegel, Marx ya había llegado a una posición que enfatizaba las contradicciones fundamentales entre la emancipación humana significativa y la institución de la propiedad privada. A partir de esto, concluyó que el "corazón" de la emancipación humana es el proletariado naciente, y que el logro de tal emancipación requerirá "la negación de la propiedad privada" (Marx 1844, 187).

Como es bien sabido, en El Manifiesto Comunista, Marx y Engels identificaron la lucha de clases como la fuerza motriz del cambio histórico y acusaron a la clase obrera internacional de la responsabilidad de suprimir y trascender el modo de producción capitalista (Marx y Engels, 1848). Se debe destacar que, no solo en estas intervenciones políticas, sino también en su trabajo científico más maduro, Marx vuelve una y otra vez a la centralidad de la lucha de clases. Por ejemplo, en el postfacio a la segunda edición del volumen I de El Capital, Marx señala que la buena recepción que El Capital tuvo "en amplios sectores de la clase obrera alemana, es la mejor recompensa por mis trabajos" (Marx 1867, 95). De manera similar, en el Prefacio 
a la edición francesa de Capital, Marx señala que hacer que el trabajo sea accesible para la clase trabajadora es, para él, una consideración que "supera todo lo demás" (Marx 1867, 104).

El antagonismo de clase y la lucha de clases, entonces, es el "fundamento de toda la política de Marx", y fundamentalmente colorea su enfoque metodológico para comprender el modo de producción capitalista (Draper 1977, 14). La dinámica fundamental que caracteriza al capitalismo es la contradicción entre la clase capitalista y la clase obrera. Como el capitalismo es un sistema basado en la expansión incesante del capital, y como esto se logra mediante la explotación del trabajo, existe dentro del modo de producción capitalista un conflicto irreducible entre los intereses de las dos clases.

El aumento de capital, es resultado de la explotación y degradación del trabajo y la clase trabajadora. Como Marx lo pone al final del volumen I de El Capital:

"todos los métodos para la producción de plusvalía son al mismo tiempo métodos de acumulación; y cada extensión de acumulación se convierte nuevamente en un medio para el desarrollo de esos métodos. Por lo tanto, se deduce que, en la medida en que el capital se acumula, la porción del trabajador, sea su pago alto o bajo, debe empeorar [...] Se establece una acumulación de miseria, correspondiente a la acumulación de capital. La acumulación de riqueza en un polo es, por lo tanto, al mismo tiempo acumulación de miseria, agonía de la esclavitud del trabajo, ignorancia, brutalidad, degradación mental, en el polo opuesto, es decir, del lado de la clase que produce su propio producto en el forma de capital" (Marx 1867, 709)

Los procesos de acumulación de capital y la reproducción del modo de producción capitalista dan como resultado un sistema de desigualdad y de falta de libertad para la clase trabajadora, además de la desigualdad sistémica concomitante que conlleva (Wright 2005).

En marcado contraste con la realidad producida por el funcionamiento del modo de producción capitalista, la ideología 
legalista liberal plantea un mundo de individuos libres e iguales, comprometidos con la búsqueda racional del propio interés, que legitima la desigualdad sistémica y el antagonismo de clase "mediante la negación de su existencia "(Wood 1988, 14). Como dijo Montesquieu, una vez que se abandona el estado de naturaleza, solo "la protección de las leyes" puede hacer que las personas sean libres e iguales (Montesquieu 1748/1949, 111). Del mismo modo, Dicey de manera muy lírica se refiere a la majestuosa igualdad ante la ley, cuando sostiene que "cada hombre, cualquiera que sea su rango o condición”, está sujeto por igual (Dicey 1915/1982, 114). Y esta tradición se mantiene viva por los teóricos contemporáneos, quienes sostienen que las fuertes protecciones legales son una "condición previa necesaria para la libertad" (Harel 2014, 7).

En contraste con esta idealización de las reglas y formas legales existentes como naturales, neutrales y propicias para la igualdad y la libertad, una tarea central de los análisis marxistas del Derecho, el Estado y los derechos es resaltar el papel que desempeñan en la estructuración y legitimación de sociedades divididas por desigualdades de clase y contradicciones. En este sentido, hay algo de verdad tanto en la afirmación de que la "jurisprudencia burguesa" es "la voluntad de [la clase dominante], convertida en una ley para todos" (Marx y Engels $1848,501)$ como en la observación de que la ley rara vez es "la expresión dura, no mitigada, no adulterada de la dominación de una clase" (Engels 1890, 60).

En este punto, todos los elementos del método de Marx discutidos hasta ahora se unen, como deben ser en cualquier análisis concreto. Las normas jurídicas, los derechos o las formas estatales siempre serán el producto de desarrollos y contiendas históricas concretas. Como tal, cualquier norma dada reflejará una combinación entre los requisitos objetivos del modo de producción y el equilibrio subjetivo de fuerzas entre las clases contendientes. Es importante tratar de poner de relieve todos estos aspectos, a fin de evitar todos los males de la reificación, el quietismo o el materialismo mecánico simplista. 
Por ejemplo, la reciente ronda de propuestas para acuerdos comerciales megaregionales (TTIP, TPP, etc. con el TLCAN como precursor temprano) es un intento de abordar la crisis estructural del capitalismo (Mészáros 1995). En este sentido, estos nuevos regímenes jurídicos propuestos responden a una necesidad estructural del modo de producción (restaurar la rentabilidad), así como a promover los intereses de facciones específicas del capital. Al mismo tiempo, estos acuerdos propuestos se opusieron a amplias colaciones de sindicalistas, ambientalistas y otros en toda Europa, Asia y América Latina. Los acuerdos propuestos se han suspendido, por ahora, hasta que resurja algo parecido a las propuestas originales, esto será producto de los requerimientos objetivos del modo de producción cambiante como de la lucha de clases.

Generalizando a partir de esto, los análisis marxistas del Derecho, el Estado y los derechos deberían enfatizar el papel que desempeñan las formas jurídicas dadas en la estructuración y legitimación ideológica de sociedades fundamentalmente divididas en clases. Al mismo tiempo, los análisis marxistas deberían estar atentos a las contradicciones que prevalecen en los regímenes dados, y el potencial dentro de ellos para promover los intereses inmediatos de la clase trabajadora y otros grupos subalternos. Como una cuestión de política, informada por las ideas del análisis materialista dialéctico, es posible apreciar que la retórica legalista y las normas jurídicas que "disfrazan la naturaleza del poder gobernante" pueden "simultáneamente" convertirse en un sitio de lucha "para aquellos que han sido desalojados del poder" (Chase 1997, 56). Este último punto es de vital importancia, porque el marxismo nos proporciona una forma de entender "la realidad social que [proporciona] la base teórica apropiada para cambiarla" (Lukács 1970, 93).

El antagonismo de clase y la lucha de clases proporcionan el punto de apoyo sobre el que depende todo el método de Marx. Unifica la comprensión dialéctica materialista de la centralidad de las contradicciones materiales que tienden hacia el 
cambio social, con la contingencia histórica y la fugacidad del capitalismo. Como tales, los análisis marxistas del Derecho, el Estado y los derechos deben ser capaces de dar cuenta de las formas desordenadas y contradictorias en las que las formas jurídicas y estatales sostienen fundamentalmente el modo de producción existente, al tiempo que median y cristalizan (por un tiempo) los antagonismos de clase en el corazón del capitalismo.

\section{Conclusión}

Como se señaló al principio, el trabajo de Marx no nos proporciona una teoría integral de todo, en la que simplemente podamos conectar datos contemporáneos y obtener la conclusión correcta. En particular, el trabajo de Marx no nos proporciona una posición clara y coherente sobre cómo debemos abordar las preguntas importantes sobre el papel del Derecho, el Estado y los derechos. Dicho esto, el trabajo de Marx nos proporciona "una plantilla básica e insustituible" (Harvey 2012, 18) sobre la cual podemos comenzar a construir nuestros propios análisis del Derecho, el Estado y los derechos hoy.

El argumento que se presenta aquí es que el materialismo dialéctico, la contingencia histórica y la fugacidad del modo de producción capitalista y la lucha de clases son los puntos de referencia metodológicos centrales que podemos y debemos tomar de Marx para informar el desarrollo de los análisis marxistas del Derecho, el Estado y derechos. Es importante recordar en todo esto que, si bien Marx se puede agrupar con Weber y otros en el panteón de los grandes científicos sociales, su trabajo representa mucho más el ser recurso crítico más. El trabajo de toda la vida de Marx fue, según su undécima tesis sobre Feuerbach, la preocupación por comprender la realidad del capitalismo, a fin de cambiarlo. No hay una manera fácil de mapear este compromiso revolucionario, en lo que respecta a los métodos, para entender el Derecho, el Estado y los derechos, pero ese es el desafío que debemos enfrentar. 


\section{Referencias}

Althusser, Louis. 1971. On Ideology. London: Verso.

Anderson, Perry. 1979. Considerations on Western Marxism. London: Verso.

Berman, Marshal. 1999. Adventures in Marxism. London: Verso.

Cain, Maureen. 1974. The Main Themes in Marx' and Engels' Sociology of Law. British Journal of Law and Society 1 (2): 136-148.

Cain, Maureen and Alan Hunt. 1979. Marx and Engels on Law. London: Academic Press.

Chase, Anthony. 1997. Law and History. New York: The New Press.

Dicey, Albert V. 1982/1915. Introduction to the Study of the Law of the Constitution. Indianapolis, en: Liberty Fund.

Draper, Hal. 1977. Karl Marx's Theory of Revolution - Volume 1: State and Bureaucracy. New York: Monthly Review Press.

Engels, Friedrich. 1890. Letter to Conrad Schmidt. In MECW Volume 49, 57-65. London: Lawrence \& Wishart.

Engels, Friedrich. 1886. Ludwig Feuerbach and the End of Classical German Philosophy. In MECW Volume 26, 353-398. London: Lawrence \& Wishart.

Fine, Bob. 1984. Democracy and the Rule of Law: Marx's Critique of the Legal Form. London: Pluto.

Harel, Alon. 2014. Why Law Matters. Oxford: Oxford University Press.

Harvey, David. 2012. History Versus Theory: A Commentary on Marx's Method in Capital. Historical Materialism 20 (2):3-38.

Holloway, John. 2012. Crisis and Critique. Capital \& Class 36(3) 515-519.

Hunt, Alan. 2004. Getting Marx and Foucault into Bed Together. Journal of Law and Society 31 (4): 592-609.

Hunt, Alan. 1992. A Socialist Interest in Law. New Left Review I/192: 105-119.

James, C.L.R. 1999. Marxism for Our Times. In Marxism For Our Times: C.L.R. James on Revolutionary Organization, edited by Martin Glaberman, 43-66. Jackson, MS: University Press of Mississippi. 
Lukács, Georg. 1971. History and Class Consciousness. Cambridge MA: MIT Press.

Lukács, Georg. 1970. Lenin: A Study in the Unity of His Thought. London. New Left Books.

Marx, Karl. 1867. Capital: A Critique of Political Economy: Volume One. London: Penguin.

Marx, Karl. 1864. Inaugural Address of the Working Men's International Association. In MECW Volume 20, 5-13. London: Lawrence \& Wishart.

Marx, Karl. 1859. A Contribution to the Critique of Political Economy. In MECW Volume 29, 257-507. London: Lawrence \& Wishart.

Marx, Karl. 1857/58. Grundrisse. London: Penguin.

Marx, Karl and Friedrich Engels. 1848. Manifesto of the Communist Party. In MECW Volume 6, 477-519. London: Lawrence \& Wishart

Marx, Karl. 1844. Contribution to the Critique of Hegel's Philosophy of Right. In MECW Volume 3, 175-187. London: Lawrence \& Wishart.

Marx, Karl and Friedrich Engels. 1845/46. The German Ideology. In MECW Volume 5, 19-539. London: Lawrence \& Wishart.

Mészáros, István. 1995. Beyond Capital. London: The Merlin Press.

Mohun, Simon. 2016. Class Structure and US Personal Income Distribution, 1918-2011. Metroeconomica 67 (2): 334-363.

Montesquieu, Charles-Louis. 1949/1748. The Spirit of the Laws. New York: Hafner Publishing Company.

O'Connell, Paul. 2018. On the Human Rights Question. Human Rights Quarterly 40 (4) [forthcoming].

Ollman, Bertell. 2003. Dance of the Dialectics: Steps in Marx's Method. Chicago: University of Illinois Press.

Pashukanis, Evgeny. 1978. Law and Marxism: A General Theory. London: Pluto.

Poulantzas, Nicos. 1978. State, Power, Socialism. London: New Left Books.

Renner, Karl. 1949. The Institutions of Private Law and Their Social Function. London: Routledge and Kegan Paul. 
Rühl, Otto. 1929. Karl Marx: His Life and Works. London: Allen and Unwin. Steinberg, Marc. 2016. England's Great Transformation. Chicago: Chicago University Press.

Sweezy, Paul. 1946. The Theory of Capitalist Development. London: Dennis Dobson Ltd.

Thompson, Edward P. 1975. Whigs and Hunters: The Origins of the Black Act. New York: Pantheon Books.

Wood, Ellen Meiksins. 1988. Capitalism and Human Emancipation. New Left Review I/167: 3-20.

Wright, Ian. 2005. The Social Architecture of Capitalism. Physica A 346: 589-620. 